\title{
APPLICATION OF THE EVOLUTION THEORY IN MODELLING OF INNOVATION DIFFUSION
}

\author{
Milan Krstic ${ }^{35}$, Ana Skorup ${ }^{36}$, Djordje Minkov ${ }^{37}$
}

\begin{abstract}
The theory of evolution has found numerous analogies and applications in other scientific disciplines apart from biology. In that sense, today the so-called "memeticevolution" has been widely accepted. Memes represent a complex adaptable system, where one "meme" represents an evolutional cultural element, i.e. the smallest unit of information which can be identified and used in order to explain the evolution process. Among others, the field of innovations has proved itself to be a suitable area where the theory of evolution can also be successfully applied. In this work the authors have started from the assumption that it is also possible to apply the theory of evolution in the modelling of the process of innovation diffusion. Based on the conducted theoretical research, the authors conclude that the process of innovation diffusion in the interpretation of a "meme" is actually the process of imitation of the "meme" of innovation. Since during the process of their replication certain "memes" show a bigger success compared to others, that eventually leads to their natural selection. For the survival of innovation "memes", their manifestations are of key importance in the sense of their longevity, fruitfulness and faithful replicating. The results of the conducted research have categorically confirmed the assumption of the possibility of application of the evolution theory with the innovation diffusion with the help of innovation "memes", which opens up the perspectives for some new researches on the subject.
\end{abstract}

KEYWORDS: evolution theory, "memes", innovation, diffusion, modelling

JEL: O31, O33, Q55

UDC: 330.45

330.341.1

\footnotetext{
${ }^{35}$ Faculty of Business Economics and Entrepreneurship, Belgrade, Serbia,e-mail: mykrstic@gmail.com

${ }^{36}$ Faculty of Business Economics and Entrepreneurship, Belgrade, Serbiae-mail: anaskorup@gmail.com

${ }^{37}$ Graduate school of proffesional studies "Prof. dr Radomir Bojković", Kruševac, Serbia,e-mail: minkov55@gmail.com
} 


\section{Introduction}

The laws passed so far have contributed to the clarification of numerous phenomena in nature. Widening the fields of new cognitions opens new unknown horizons which are worth of further research. Past researches have often pointed to some elements of analogy, based on which, the ideas taken from a scientific field were applied for the solution of suitable problems in other fields where it was mostly about partial acts, restricted to certain specific fields (Bulat, 2000).

As the confirmation of the analogy in the field of natural sciences the analogy can be named between the electric and mechanical systems, which is also manifested through the existence of an analogy between the equations which describe their behaviour. In that way it is possible to introduce the analogies of the electric system and suitable mechanical systems and vice versa (Bakshi, Bakshi, 2009).

In the context of quoted applications of analogies in other fields, it can be talked about the application of Darwin's Theory of Evolution, especially the Law on natural selection in the interpretation and studying of innovation diffusion.

When it comes to Darwin's Law on the Natural selection, Sir Karl Popper (Radnitzky,Bartley, 1993) states his point of view: "My selection was that the doctrine of natural selection is the highest metaphysical research programme. That causes detailed problems in many areas, and that tells us what we would expect from an acceptable solution of these problems. I still believe that natural selection works this way as a research programme".

Genrich Altshuller (1926 - 1998), a famous Soviet inventor and author of the TSPI theory - Theory of Solving Problems Inventively (Lerner, 1991) discovered that technical systems do not evolve by accident, but their evolution follows certain patterns which he called the "evolution laws". The evolution laws are patterns of the evolution which characterize the evolution of technical systems and can thus help predict their development in the future (Leon, 2006).

Based on Darwin's Law on Natural Selection, Dawkins introduced a generalization of laws on natural selection, where the cultural transmission is analogous to genetic transmission, with which he widely opened the door to the application of evolution theory in other scientific disciplines.

Dawkins (Dawkins , 1999) starts from the Evolution law that life as it is known to us evolves with differential surviving by replicating entities. The replicative entity, prevailing on Earth is the DNA molecule, i.e. the gene. It does not exclude the possibility of existence of other replicative entities as well, which will, on condition of fulfilling of certain conditions, start producing their replicas (copies) and "almost inevitably tend to commence the new evolution of its kind". Moreover, he considers that since recently on this planet a new kind of replicators has appeared. They still float in their "seminal soup", but are already achieving evolutional changes which highly surpass the genes in that. New seminal soup is created from human culture. The culture personalized in its manifesting elements such as language, fashion, food, religion, customs, art, architecture, engineering, technology and other, as viewed in historical time develops in such a way that one gets the impression that it is a very accelerated genetic evolution, although culture has absolutely no connection with genetic evolution.

In searching for the adequate name for a new replicator, Dawkins introduced the term "mieme" which has a Greek root, but he shortened it into meme in order to make an analogy with the biological replicator gene. Meme is" a noun which expresses the idea of a unit of 
cultural transfer, i.e. the unit of imitation". The examples of memes can be melodies, ideas, phrases, clothes fashion, the way of making pots, etc.

Memes are promoted in the pool of memes, analogously as the genes do in the pool of genes, walking from a person (brain) to person (brain) through the process of self-replicating, which in the broader sense can be called imitation. As in the natural selection not all the genes in the pool of genes are equally successful in replication, the analogy works for all the memes in the pool of memes. For the survival of replicators, particularly memes, three characteristics are the key ones: longevity, fruitfulness and faithful replication. Longevity is about how long the memes are going to stay in the head (brain) of a person. Fruitfulness implies how much the meme is acceptable by the people acceptors. Faithful replication is the matter of communication and it deals with degradation of the message during the transfer of information.

The quoted theory based on the evolution of memes - "meme-evolution", today is already widely accepted. It can be said that memes represent a complex, adaptable system where a meme can represent an evolutional cultural element, i.e. the smallest unit of information which can be identified and used to explain the evolution process.

Meme evolution has found its application in various fields of social sciences. Some examples of the application of memes on solving particular problems are worth mentioning. That is why two examples of such application will be presented in the following part of the text.

The first example is Simulation of innovation of technical artefacts by (Khanafiah, Situngkir, 2004). Evolution is the process of a gradual change, by which the simpler kinds are transformed into more and more complex kinds by cumulating characteristic changes in inheriting, from generation to generation. Due to the activity of evolution the descendant of the kind, unlike his ancestor, will have several different characteristics. In that sense Phylogenetic analysis is used to present the cluster of all the descendants of one common ancestor. Phylogenetic analysis is usually interpreted as a system of branching of a tree, or the diagram known as the phylogenetic tree, and it is conducted by a systematic analysis, through making of the history of the species and the evolution of the relation between the descendants and their ancestors, based on the similarity of characteristics as the basis of comparison. From the meme perspective, an innovation can be considered an accidental mutation of the code of meme (artefact). Mutation is seen in the replacement of one code with another code of the meme (artefact). Artefact is the phenotypic meme (or a phemotype) which came from its genotype (memetype). In the particular case, a technological artefact is a mobile phone of the brand Nokia, whose meme evolution is researched, picture 1.

It is evident from the work that the methodology of the application of memes can be successfully used as a perspective analytical tool for the analysis of technological innovation.

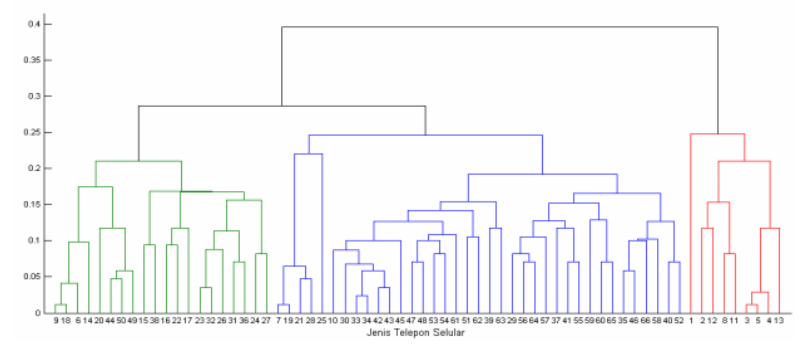

Figure 1:The Phylomemetic tree of a Nokia phone made by the application of UPGM Unweighted Pair Group Method with Arithmetic Means

Source: Khanafiah, Situngkir( 2004) 
The second example is the Study of economic development on the side of demand (by Dahlan, Situngkir, 2010).The evolutional economy contains new entities which have different qualitative characteristics. The idea of qualitative change makes it possible to consider three important phenomena in economic life: innovations, substitutions of products and transformations of consumers' behaviour. The evolution of demand process has been researched from the point of meme. In particular case there are two kinds (sequences) of meme (memeplex) which represent the economical product as well as the preference of consumers. The evolution model of demand sees the usefulness as the function of the distance between two kinds (two types of sequences) of memes (memeplex), which represent economic products and preferences of consumers. An innovation is defined as a change in the kind of memes on the specific economic product. In the result of the analysis there are 4 kinds of demand (Table 1), i.e.: "statistical demand", "dynamic demand without evolution", "demand limited by the evolution", and "viable evolution of demand".

Table 1: The conditions of demand depending on the presence of innovation

\begin{tabular}{||l|l|l||}
\hline States of demand & Without innovation & There is innovation \\
\hline $\begin{array}{l}\text { Without the } \\
\text { transformation of } \\
\text { preference }\end{array}$ & $\begin{array}{l}\text { "Statistical demand" } \\
\text { no dynamics or qualitative } \\
\text { change }\end{array}$ & $\begin{array}{l}\text { "Demand limited by the evolution" } \\
\text { dynamic demand, but qualitative } \\
\text { characteristics can be trapped in a } \\
\text { quasi-stabile state }\end{array}$ \\
\hline $\begin{array}{l}\text { There is a } \\
\text { transformation of } \\
\text { preference }\end{array}$ & $\begin{array}{l}\text { "Dynamical demand without } \\
\text { evolution" } \\
\text { only dynamics requests, but not } \\
\text { the evolution }\end{array}$ & $\begin{array}{l}\text { "Sunainable evolution of demand" } \\
\text { qualitative change except for the } \\
\text { most superior and the most inferior } \\
\text { products }\end{array}$ \\
\hline \hline
\end{tabular}

Source: Dahlan, Situngkir(2010)

Starting from the principle of application of memes in the quoted cases, the authors are introducing the hypothesis that similar principles, i.e. evolutional theory based on memes is possible to apply in the case of considering the process of innovation diffusion. In that sense a theoretical research has been conducted whose results will be presented in the further text of the work.

\section{Diffusion of innovations}

Based on the process definition (Krstić, 2013) innovation can be understood as an innovational process (or a cluster of innovational activities), i.e. a specific process in which an idea is born about the need of carrying out a change (creating ideas), then a change is conducted up to the level of its commercialization (realization of invention), and in the end it is adopted by a certain social system (diffusion). So, a complex innovational process, in a relatively simplified vision, can be presented by a sequential process, which consists of three key sub processes, or phases (Figure 2), such as:

- The first phase - creating of the idea is the phase which directly precedes the invention;

- The second phase - of the realization of invention is the phase which directly precedes the innovation; and

- The third phase - diffusion of the innovation is the phase which directly precedes the level of acquiring the innovation. 
The way out of the second phase are inventions, or commercially promising ideas. The way out of the second phase are realized innovations, or the ideas brought to commercial application. The way out of the third phase is the level of acquiring the innovation, i.e. the diffusion of innovation.

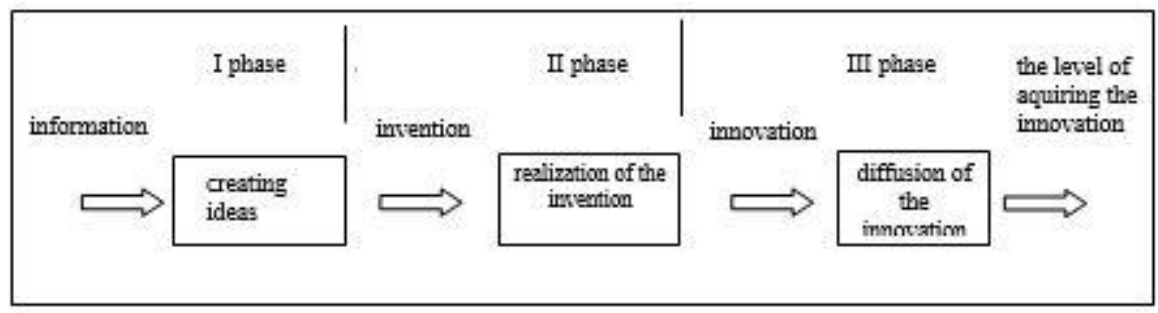

Figure 2: Phases of innovational process

\section{Source: Krstić (2013)}

Diffusion of innovations can be defined as a process by which an innovation is acquired and its acceptance by an individual is achieved (an individual, a person) or a certain social system (a certain group of people). The basic elements of diffusion of innovations are: innovation, communicational channels, time and a social system.

The theory of diffusion has four basic regularities and they are: innovational decisionmaking, individual innovativity, the level of acquiring and the attributes of perception.

Innovational decision-making is the regularity of the diffusion of innovations which is related to decision making about accepting innovations by an individual (a group of people). Innovational decision-making is a happening concerning innovations which lasts, i.e. the process which takes place in time and goes through the following stages: discovery about an innovation, persuasion about the innovation, decision-making about the innovation and confirmation about the innovation.

Individual innovativity is a regularity of the diffusion of innovations which is related to the distribution of individual characteristics of people which can be presented by the bellshaped percentage distribution of the division of certain categories of people by acquiring innovation. Based on the presented, people can be classified in the following categories of acquirers looked at from the left to the right of the distribution into: innovators, which represent up to $2.5 \%$ of the human population; early acquirers, which represent up to $13.5 \%$ of the human population; early majority, which represent up to $34 \%$ of the human population; late majority which represent up to $13.5 \%$ of the human population and the ones left behind which represent some $16 \%$.

The level of adoption is the regularity of diffusion of innovations by which it takes place constantly all the time during the lasting of the innovation, i.e. the life cycle of the innovation and it expresses the level by which the innovation has been acquired, and it is represented by the co-called s-curve, which shows the character of adoption of the innovation. According to it the adoption of the innovation first goes through the period of slow and gradual growth, then through the period of a relatively dramatic or rapid growth of adoption of the innovation, and in the end it comes to the gradual stabilization and possible slowdown of adoption of the innovation.

The attributes of perception represent the regularity of diffusion of innovations which comprises the main characteristics of the innovation related to which the potential adopters most often mark and rate an innovation, and those are: usefulness, the possibility of a trial, a relative advantage, visibility, complexity and compatibility. 


\section{Modelling of innovation diffusion from the perspective of memes}

In order to interpret the modelling of diffusion of innovations from the perspective of memes, one should start from the process definition of an innovation presented in picture 2 . The third phase of the quoted innovation process has been set aside as a separate picture and is presented in picture 3, and can now be viewed as a separate independent process, i.e. the process of diffusion. It is evident from the picture that the innovation is an entrance into the process of diffusion of innovations, and that the exit from the process of diffusion represents the level of its adoption by a certain social system (a social group). Of course, by the innovation on the entrance into the process of diffusion, in this interpretation a cluster of relevant information is implied about the innovation which has just appeared.

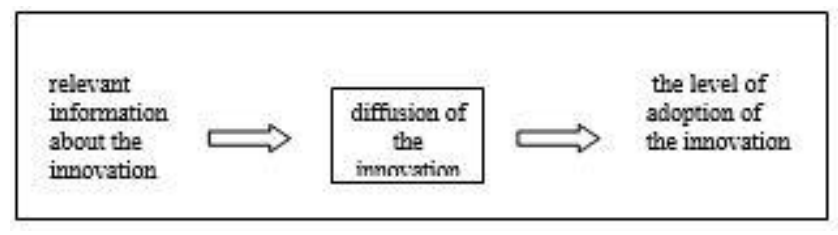

Figure 3: The process of diffusion of the innovation

\section{Source: Authors}

Since in the general case a meme is the replicative carrier of information about an entity, in the particular considered case when it is applied to the process of innovation diffusion, which is presented in the picture 3 , it can be concluded that at the entrance to the process of diffusion there lies the meme of the innovation.

As soon as a certain innovation appears, or a relevant information about the innovation becomes available, the conditions are made for forming the meme of innovation (a replicator) which alone takes over the role of replicating and begins to make its own replicas (copies), and with this the evolution of that kind of meme begins. In the wider sense, the described appearance can be called an imitation, which, according to Dawkins (1999), implies a process within which the memes are propagated.

If everything said before is taken into consideration, it can be concluded that the process of diffusion of innovations in the interpretation of a meme is actually the process of imitation of the meme of innovation.

During the process of replicating of the meme of innovation from the pool of memes, not all the memes of innovations are equally successful, actually some of them are more successful than others, which eventually leads to their natural selection. For the survival of the meme of innovation three characteristics are the key ones, and they are: longevity, fruitfulness and faithful replicating.

Longevity of the meme of innovation depends on where and how it is kept. If the meme of innovation is kept only in the memory, or the head (brain) of a person, its longevity will depend on the duration of memory of the given person and it is limited by the human lifespan, but if it is saved and/or some hard copy medium (printed, CD, DVD, memory card, etc.) its longevity can be significantly prolonged.

The fruitfulness of the meme of innovation depends on how much the meme of innovation has been acceptable by the people acceptors. Replicating, or the survival of a meme of innovation will depend on how much the meme is acceptable from the point of view of potential users of the innovation. This dimension of the innovation meme can also be 
quantitatively expressed. For example, the number of years necessary for a certain innovation meme to reach 50 million of carriers (users). Thus it took 75 years for the telephone, 38 years for the radio, 13 years for television, 4 years for the internet, 3.5 years for Facebook, 35 days for the game Angry Birds (WSJ, 2015). From the above quoted it can be concluded that from the perspective of a meme, the innovation diffusion - is the fruitfulness of the innovation meme, or the speed of replicating, figure 4.

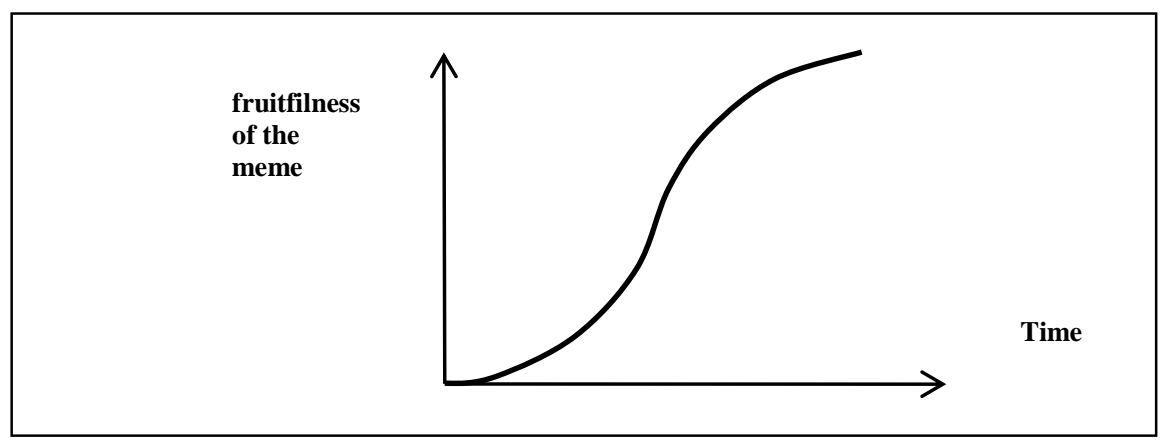

Figure 4: The fruitfulness of the innovation meme

Source: Author

The faithfulness of replicating of the innovation meme is the thing which concerns communication and is related to degradations of the message, to which it comes during the transfer of information. It is known that the communication chain forms the set of elementary communication connections. The longer communication chain, i.e., as the number of transmission points increases, the probability of deformation of the message in transfer increases as well. (Lewis, 1987)

From the characteristics of the faithfulness of replicating comes the fact that the innovation memes are transferred from people to people in a changed shape. It seems that the transmission of the innovation meme is rather the subject of a continuing mutation due to deformation of the message than the result of recombination of memes in the pool of memes.

In the pool of memes there are several kinds of memes, for example, Facebook, Twitter, LinkedIn and so on. Among the innovation memes, the competition is set up, it can be said that they indulge in some sort of a competition with each other, not only on the basis of affection of attention, but also based on information resources.

Based on affection of attention innovation memes of an individual person (or the person's brain) fight for supremacy in the attention of a person compared to the rival memes. If an innovation meme attracts the attention of a person (brain) in a larger scope, it has to do it on the account of decreasing the attention of the person to another innovation meme - a rival, i.e. the competitor.

Based on information resources innovation memes compete with other innovation memes for supremacy over resources which are crucial for communication. In other words, the resources for which innovation memes compete are time (within electronic mass media, for example radio, $\mathrm{TV}$, the internet,) and space (written, printable, exhibition, advertising and others, such as for example space in newspapers, on a fair, on a billboard, etc.). 


\section{Regularities of diffusion from the perspective of a meme}

In order to make the mosaic of innovation diffusion from the perspective of a meme, in further text, the basic regularities of diffusion are considered from the perspective of a meme (innovational deciding, individual innovativity, the degree of acquiring and the attributes of perception).

Innovational decision making from the perspective of the innovation meme is accepting the meme and it is related to making decisions concerning the acceptance of meme by an individual or by more of them (a group of people). The acceptance of a meme, or the process which takes place in time goes through the following steps: the knowledge of a meme, the persuasion about the meme, decision making about the meme and the confirmation of the meme.

Individual innovativity from the perspective of innovation meme is the individual acceptability of the new memes. It is related to the division of individual characteristics of people in the view of accepting the new memes and can be presented also by a bell-shaped percentage distribution of divisions of the certain categories of people by the issue of the speed of acquiring the meme, which viewed from the left to the right of the distribution consists of: meme innovators, which make $2.5 \%$ of the human population; early meme acquirers which make up to $13.5 \%$ of the human population; late meme majority, which make up to $34 \%$ of the human population and meme delayers who make up to $16 \%$ of the human population.

The level of acquiring from the perspective of a meme is the fruitfulness of the meme, picture 4. It is represented by the continuous process which throughout the whole time of lasting of the meme expresses the level to which the meme has been acquired, and it is interpreted by the so-called s-curve, which shows the character of acquiring of the meme, starting with the period of a slow and gradual growth, continues with a period of a relatively dramatic accelerated growth and finally finishes with a slower growth.

The attributes of perception from the perspective of a meme comprise main characteristics, or the attributes of a meme related to which the potential acquirers most often evaluate and rate them, and these are: usefulness, possibility of a trial, relative advantage, visibility, complexity and compatibility of the innovation.

\section{The basic elements of the diffusion of innovations from the perspective of a meme}

In order to complete the mosaic of innovation diffusion from the perspective of a meme, in further text from the perspective of a meme, the basic elements of diffusion of innovations are considered (innovation, communication channels, time and social system).

Innovation from the perspective of memes is a meme (of innovation) which can be considered new for a person or a certain group of people.

Communication channels from the perspective of a meme represent the way in which memes travel from one person (brain) to another.

Time from the perspective of memes is the dimension of a meme which appears first with the acceptance of a meme, as a frame of the fruitfulness of a meme.

The social system from the perspective of memes is represented by a person (the brain of the carrier of a meme) or the cluster of people (brains carriers of memes). 


\section{Results and discussion}

The results of this research have made it possible for the innovation diffusion to be presented in the meme domain, i.e. from the perspective of memes, as it was done in figure 5.

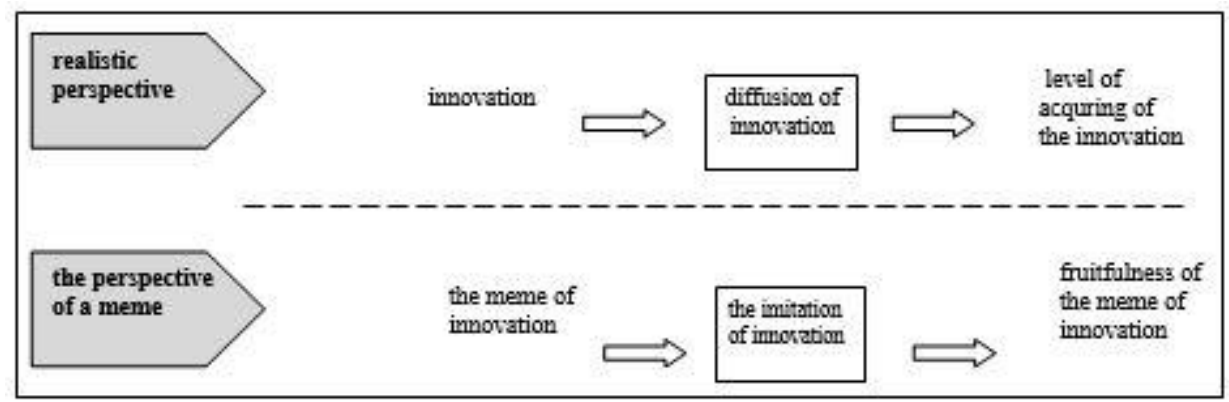

Figure 5: The process of diffusion of innovation from the realistic and meme perspective

\section{Source: The author}

Since the diffusion process is built (and represented) by the relevant factors of the process (regularities and basic elements), the quoted factors are also represented with suitable meme elements. The meme presentation of relevant factors of the process has made it possible to make their table with a comparative account of the realistic and meme perspective, table 2 .

Table 2:Relevant factors of the process of diffusion of innovation from the realistic and meme perspective

\begin{tabular}{|l|l|l||}
\hline \multirow{4}{*}{$\begin{array}{l}\text { Regularities of } \\
\text { diffusion }\end{array}$} & Realistic perspective & Meme perspective \\
\cline { 2 - 3 } & inovational decision-making & acceptance of a meme \\
\cline { 2 - 3 } & individual innovativity & $\begin{array}{l}\text { individual acceptability of the new } \\
\text { memes }\end{array}$ \\
\cline { 2 - 3 } & level of adoption & fruitfulness of memes \\
\cline { 2 - 3 } $\begin{array}{l}\text { Elements of } \\
\text { diffusion of } \\
\text { innovation }\end{array}$ & attributes of perception & attributes of memes \\
\cline { 2 - 3 } & innovation & meme \\
\cline { 2 - 3 } & Time & the way memes travel \\
\cline { 2 - 3 } & social system & dimension of memes \\
\hline
\end{tabular}

Source:The author 


\section{Conclusion}

The theory of evolution has found numerous applications and analogies in other fields of science. From the realized cases of practical application of evolution theory out of biological sciences so far, the scientific field of innovations has proved to be very suitable for that purpose, which was confirmed by some examples of application, which were presented in the paragraph of Introduction of this work.

In this work it all started from the assumption that the evolution theory, or the theory of meme is possible to apply successfully in the interpretation of diffusion of innovations. The findings to which the authors came, which are presented in the paragraph Results and discussion of this work, unambiguously confirm the correctness of the introduced assumption.

When it comes to the diffusion of innovations the results of the research offer the possibility to explain more closely the question of how to conduct the diffusion of innovations.

Thanks to this work, the diffusion of innovation has been interpreted from the perspective of memes by which the assumptions were made for further researches in this field.

\section{References}

[1] Bakshi U.A, Bakshi V.U. (2009). Automatic Control System, First Edition,. Technical Publications Pune, India.

[2] Bulat V. (2000). Opšti zakon dinamčkog uravnoteženja. Kruševac: ICIM - Izdavački centar za industrijski menadžment.

[3] Dahlan RM, Situngkir H. (2010). Evolution of Consumers' Preferences due to Innovation. Retrieved from MPRA Munich Personal RePEc Archive: http://mpra.ub.uni-muenchen.de/24159/

[4] Dawkins R. (1999). "The Selfish Gene", [ First published 1976; 1989 edition: Oxford University Press, ISBN 0-19-286092-5 (paperback) ]. Retrieved 08 15, 2015, from http://www.rubinghscience.org/memetics/dawkinsmemes.html.

[5] Jevtić, B., Vučeković, M., Radulović, D., (2014) Technological Innovations - Evidence from Serbia, International Review (2014 No. 3-4), Faculty of Business Economy and Entrepreneurship, Belgrade, pp.27

[6] Kåhre J. (2002). The Mathematical Theory of Information, Springer Science +Business Media New, York.

[7] Khanafiah D, Situngkir H. (2004). Innovation as Evolution, Case of Study: Phylomemetic of Cellphone Designs, . Retrieved 08 19, 2015, from WPV2004 Bandung Fe Institute: http://arxiv.org/abs/nlin/0412043

[8] Krstić, M. (2013). Upravljanje inovacijama. Beograd: Visoka škola za poslovnu ekonomiju i preduzetništvo.

[9] Leon N. (2006, 08 22). Trends and patterns of evolution for product innovation. Retrieved 2015, from The Triz Journal: http://www.triz-journal.com/trends-patternsevolution-product-innovation/

[10] Lerner L. (1991). Genrich Altshuller: Father of TRIZ . Russian Magazine Oganok . 
[11]Lewis, V. Ph. (1987). Organizational Communication: The Essence of Effective Management. N.Y : Prentice - Hall, Engelwood Cliffs.

[12] Radnitzky G, Bartley W.W. (1993). Evolutionary Episetemology, Rationality, and the Sociology of Knowledge. Third Printing: Open Court Publishing Company.

[13] Rogers M.E . (1983). Diffusion Of Innovations, Third Edition, . The Free Press, A Division of Macmillan Publishing Co., Inc.

[14]WKP. (2015). Karl Popper. Retrieved 08 20, 2015, from Wikipedia: https://en.wikipedia.org/wiki/Karl_Popper

[15] WSJ. (2015). It Took the Telephone 75 Years To Do What Angry Birds Did in 35 Days. But What Does That Mean? Retrieved 08 25, 2015, from The Wall Street Journal: http://blogs.wsj.com/economics/2015/03/13/it-took-the-telephone-75-years-to-dowhat-angry-birds-did-in-35-days-but-what-does-that-mean/

\section{Article history:}

- $\quad$ Received 19 February 2016

- Accepted 20 April 2016 